\title{
World Mental Health Day 2020: Stress Levels at it's Peak during Pandemic Times?
}

The world is facing an unprecedented crisis in 2020: From Healthcare workers to teachers to the common labourer, all are facing the heat due to this so called "New Normal". As per the World Health Organization, Bereavement, isolation, loss of income and fear are triggering mental health conditions or exacerbating existing ones and thus increasing the prevalence of mental health problems among people.

The initiative to celebrate October 10 as the World Mental Health Day was done in the year 1994; and in 2020, the theme is aptly chosen as "Mental Health for All- Greater Investment - Greater Access". Fear, stress, and worry were normal were the few responses people perceived in the context of the COVID-19 pandemic. During this pandemic, restricted movements, work from home, unemployment, no socialization has taken one's mental and physical health for a toss. A person is also constantly trying to sanitize daily use items posing as an additional burden. $^{2}$

A WHO survey states that current pandemic has led to either a disruption or halt in critical mental health services in $93 \%$ of countries, although the demand for mental health is increasing with every passing day. In addition, most healthcare services and workers are directed towards the prevention of COVID-19, leaving little focus on one's mental health. Many countries $(70 \%)$ have adopted telemedicine or teletherapy to overcome disruptions to in-person services, there are significant disparities in the uptake of these interventions, one of which includes disruption in internet services and poor network coverage.

The three most common misconceptions are: "My problems are not serious enough to seek therapy and only weak people go to therapy", "Once I begin therapy, I will be in it forever" and "I will be forced to take medications and will get addicted to them". We all deserve to feel safe and supported when talking about our mental health. But too often, mental health stigma leaves people feeling isolated and ashamed. At worst, it prevents people getting support, finding employment or having open conversations. ${ }^{3}$

The dilemma every year one adult in four, along with one child in ten, will have a mental health issue. These conditions can profoundly affect literally millions of lives, affecting the capability of these individuals to make it through the day, to sustain relationships, and to maintain work.

There are however, a few ways to prevent stress:

1. Surround Yourself with Positivity

2. Exercise

3. Eat Mental Health Boosting Foods

4. Share Your Feelings

5. Sleep Enough

Last, but the least, a person should believe that "it is ok to seek help, either from friends or professional help". One should remember that "there is not joy greater than life itself!!"

In the end, I request all readers to be on the lookout of any such potentially depressed/stressed person and try to provide assistance in the best possible way, even if it means leaving the person alone for some time and raise concern, if the need arises.

\section{REFERENCES}

1. Kumari J. World Mental Health Day 2020: History And Significance of The Day. Online Article Available from: https://www.india.com/lifestyle/world-mentalhealth-day-2020-history-and-significance-of-the-day4168527/. [Last Accessed on $25^{\text {th }}$ September, 2020] 2. Daniels I. Mental Health for All Greater Investment - Greater Access. Everyone, everywhere. (Message from the WFMH President) Online Article. Available from: https://wfmh.global/world-mental-health-day2020/ [Last Accessed on $25^{\text {th }}$ September, 2020] 3. World Health Organization. Analysing Disrupted Health Sectors. A Modular Manual. Online PDF. 
Available from: https://www.who.int/hac/techguidance/tools/disrupt ed sectors/adhsm.pdf [Last Accessed on $26^{\text {th }}$ September, 2020]

Cite this article as:

Thakar S. World Mental Health Day 2020: Stress Levels at it Peak during Pandemic Times?.

Int Healthc Res J. 2020;4(7):EC1-EC2. https://doi.org/10.26440/IHRJ/0407.10121

\section{AUTHOR AFFILIATIONS:}

Co-Editor, International Healthcare Research Journal

Assistant Professor, Department of Public Health Dentistry, School of Dental Sciences, Sharda University, Greater Noida

(ORCID ID: https://orcid.org/oooo-0oo2-8686-5309)

e-mail id for correspondence: sahil.ihrj[at]gmail[dot]com 